\title{
Original Research \\ Knowledge and attitudes towards sexually transmitted illnesses (STIs) among the general population of Saudi Arabia
}

\author{
Wafa Fageeh ${ }^{1, *}$, Bana Fakieh ${ }^{1}$, Majda Addas ${ }^{1}$, Rana Baghdadi $^{1}$, Razan Almokri ${ }^{1}$, \\ Salam Sait ${ }^{1}$, Samiha Fagih ${ }^{1}$, Sereen Alahmadi ${ }^{1}$ \\ ${ }^{1}$ Department of Obstetrics and Gynecology, King Abdulaziz University Hospital, 21589 Jeddah, Saudi Arabia \\ *Correspondence: fageeh.wafa@gmail.com (Wafa Fageeh) \\ Academic Editor: Michael H. Dahan \\ Submitted: 2 October 2021 Revised: 21 December 2021 Accepted: 28 December 2021 Published: 19 January 2022
}

\begin{abstract}
Background: We aim to determine the level of general knowledge and attitudes among the population of Saudi Arabia regarding sexually transmitted illnesses (STI). In addition, we aim to educate participants about the most common STIs, and explore how this influences the participants' attitudes and perceptions. Methods: This study is a cross-sectional web-based survey of the general population of Saudi Arabia. The sample was enrolled randomly by distributing the survey through social media over a two-month period. 420 subjects between the ages of (15-60) participated in the study. Results: Among the 420 total responses, 405 (96\%) participants were included based on the absence of missing data in their answers. Most of the participants (77\%) were females. More than half of the respondents were single $(59 \%), 24$ years old or more (57\%), Saudi $(52 \%)$, and had a bachelor's degree $(65 \%)$. Forty-eight percent $(48 \%)$ of the participants were related to the medical field. Only $11 \%$ knew someone previously diagnosed with STIs. The mean score of overall knowledge about STI was $8.79 \pm 3.17($ median $=9$ ) out of a maximum score of 20 . The scores ranged from $2-16$. A higher percentage of the participants $(48.6 \%)$ had a low level of knowledge. Two-hundred eighty-one participants showed interest in viewing the attached educational material and subsequently completed questions on attitude regarding STI education. The mean score for attitude was 5.89 \pm 1.52 out of a total of 7 (median $=6$ ). Around $73 \%$ of all participants had a positive attitude towards STI education. Conclusion: Our findings suggest that targeting the younger population by incorporating STI-related educational material into school curricula would overcome the stigma associated with these illnesses by raising awareness and improving attitude towards them.
\end{abstract}

Keywords: Sexually transmitted illnesses; Knowledge; Attitude; Awareness

\section{Introduction}

Sexually transmitted illnesses (STIs) are globally recognized as significant health burdens [1]. They have been linked to devastating complications like infertility, neurological deterioration, overwhelming immunodeficiency, and chronic hepatitis with its life-threatening sequelae [25]. Moreover, the vertical transmission of STIs can result in lifelong debility among the offspring of those infected [6]. Luckily, those infections are generally preventable, mostly manageable, and sometimes curable [7]. However, the achievement of positive outcomes is dependent on advancements in preventive medicine and public awareness. These factors are hindered by several local factors.

The field of sexually transmitted illnesses is universally regarded as underdeveloped in the Middle East generally and in the Gulf Region specifically [8]. There is an established deficit of knowledge regarding STIs and relevant behaviors [9-12]. Baazeem et al.'s [8] review of challenges to practicing sexual medicine in the middle east cites the stereotypical patriarchal structure, societal norms and the mainstream views of taboos as causes for this defecit.

Local epidemiological studies reveal a relatively low incidence of reported STIs in Saudi Arabia. Out of 68,886 cases reported between 2005 and 2012, non-gonococcal urethritis, trichomoniasis, and HIV where of the highest prevalence [13] with a noted increase among the Saudi population's contribution to the HIV (compared to non-Saudi citizens, which previously constituted the majority of cases in Saudi Arabia) [14] Furthermore, the true incidence is thought to be under-estimated due to underreporting by affected individuals [15]. Notably, $92 \%$ of cervical tumors in the kingdom were found to be HPV-related [16].

Although factors such as widespread male circumcision and the overall prohibition of extra-marital sexual activity imposed by religious and cultural beliefs are thought to correlate with low rates of STIs locally, a review of published literature highlights several inconsistencies and threats to public health $[17,18]$.

While it is thought that the prevalence of extra-marital sexual activity is non-existent, one study reports that $31 \%$ of its all-male participants had engaged in premarital sexual activity at least once [19]. Similarly, a larger study on behaviors of male adolescents revealed that $38 \%$ had experienced sexual contact, while $67 \%$ had friends who had experienced sexual contact [20]. Other authors recognized that members of the local community, particularly adolescents, obtain their knowledge on sexual matters through "friends and media" as opposed to reliable sources such as 
school-based programs or health professionals [11]. This could be responsible for the author's other findings like the mismatch between the population's perceived and actual knowledge on STI's in general and HIV specifically. Likewise, Tholoth et al. [10], reported that $71.7 \%$ of the sample reported the "internet" as their primary source of knowledge vs only $35.1 \%$ and $11.2 \%$ depending on school and parents respectively. In another study, $(88.5 \%)$ shared that they could not openly discuss their sexuality with their parents [20].

In the absence of parental guidance and accessibility to reliable sources of information, misconceptions and false beliefs are widely prevalent [18]. Balbeesi et al. [9] reports widespread misconceptions like the potential transmission of STIs via contaminated beds, utensils, and shaking hands. Better knowledge correlated with younger age, higher level of education, and higher monthly income. A notable study conducted at a large scale among attendees of Ministry of Health $(\mathrm{MOH})$ hospitals in various regions of Saudi Arabia between 2013 and 2014 showed: $75.8 \%$ did not use condoms in the presence of STI symptoms [9]. Several studies show that relative to other STIs, HIV knowledge is superior $[9,10]$. Likewise, Tholoth reports that $94.08 \%$ recognized HIV as an STI vs only $43.61 \%$ and $34 \%$ knew that HSV and HPV are sexually transmitted, respectively. Although an interesting finding reported by Raheel et al. [19] is that $20 \%$ of the Riyadh-based population of males were not aware that HIV could be transmitted through both homosexual and heterosexual contacts.

More authors have studied HIV/AIDS in the context of Arab societies. Barss et al. [15] underscored the role of locoregional factors such as wars and displacement in promoting the trafficking of sex workers and risky behaviors. This, combined with a young under-informed population and an older stigmatizing society, can propagate a cycle of HIV transmission, under-reporting, and delayed interventions [15]. Their study concluded that highschool students exhibited inadequate knowledge and suboptimal attitudes towards HIV, but an interventional workshop led to improved outcomes especially among females [14]. Larger-scale studies across the Arabian Penninsula further supported the deficits in both knowledge and attitude [21]. The necessity to isolate HIV-positive individuals, poor understanding of methods of transmission, and refusal to visit/treat infected individuals are among some of the views held by participants in similar studies [15,21,22]. A common concern among authors exploring the sensitive subject of STI transmission in a conservative setting is that compassion towards seropositive individuals is perceived as tolerance towards the socially and religiously unacceptable practices that lead to its transmission [22]. This may explain the pattern of poor attitude displayed in various studies towards STIs in general and HIV specifically.
The gaps in knowledge are compounded by other often neglected obstacles such as societal denial and low rates of incidence which stand as an obstacle to the normalization of reporting symptoms and seeking medical attention when appropriate. However, considering the increasing societal appreciation for women and women's health, we expect to witness an increased tolerability for issues pertaining to sexual medicine in the context of STIs among others. Therefore, we aim to explore current trends in knowledge, attitudes, and perceptions of sexually transmitted illnesses. Since prior authors have highlighted the necessity to strengthen efforts made to educate members of society on STIs [11,23], we also incorporated an educational element to our study in order to assess the public's attitude towards STIs after acquiring reliable information on the topic. Our educational material highlighted the most common STIs, presentation, incubation period, complications and methods of treatment and prevention when applicable. In light of the various societal obstacles described above, we expect our data to show profound defects in knowledge and attitude. However, we anticipate positive outcomes following our educational intervention.

\section{Methods}

\subsection{Study design, population, and ethical approval}

This study is a cross-sectional web-based survey of the general population. A minimum sample size of 385 participants was generated by the web-based "Raosoft sample size calculator" with a confidence level of $95 \%$ and an accepted margin of error of 5\%. The sample was enrolled randomly by distributing the survey through social media between February 2021 and March 2021. This yielded a total of 420 responses. Participants were screened for eligibility based on their age (15-60). We selected this age group to compare the younger dependent generation aged 24 or less, including those presumed to be at the high schooluniversity level, to older independent individuals in order to highlight any trends in knowledge and attitude across generations. Since our survey was randomly distributed through social media, the response rate could not be calculated. The respondents' identities remained anonymous during all phases of the study, including statistical analysis periods. The ethical approval was obtained from the Unit of Biomedical Ethics (King Abdulaziz University, Jeddah, Saudi Arabia).

\subsection{Questionnaire and assessment scores survey}

The distributed questionnaire was composed of four parts (Supplementary material 1). The first part extracted social characteristics such as (age, gender, nationality, marital status, education level, relation to the medical field, and whether the participants know anyone diagnosed with STIs). The second part was designed to assess the level of knowledge regarding STIs. It was composed of 20 questions; each weighing one point if answered correctly by the 
Table 1. Social characteristics of the sample and their association with the level of knowledge $(n=405)$.

\begin{tabular}{llllllll}
\hline Variables & Responses & Level of knowledge $(\mathrm{n})$ & Chi-Square test & $\begin{array}{c}\text { Phi or Cramer's } \\
\text { V tests }\end{array}$ \\
\cline { 2 - 7 } & $n$ & $\%$ & $\begin{array}{c}\text { Adequate } \\
(\mathrm{n}=177)\end{array}$ & $\begin{array}{c}\text { Inadequate } \\
(\mathrm{n}=228)\end{array}$ & $d f$ & $p$ value & (If required\#) \\
\hline
\end{tabular}

Age

\begin{tabular}{|c|c|c|c|c|c|c|c|c|}
\hline & $<24$ & 173 & 42.7 & 87 & 1 & $0.021 *$ & 0.115 (Moderate) & 86 \\
\hline & $\geq 24$ & 232 & 57.3 & 90 & & & & 142 \\
\hline \multicolumn{9}{|l|}{ Gender } \\
\hline & Male & 92 & 22.7 & 47 & 45 & 1 & 0.104 & $\mathrm{~N} / \mathrm{R}$ \\
\hline & Female & 313 & 77.3 & 130 & 183 & & & \\
\hline \multicolumn{9}{|l|}{ Nationality } \\
\hline & Saudi & 211 & 52.1 & 90 & 121 & 1 & 0.657 & $\mathrm{~N} / \mathrm{R}$ \\
\hline & Non-Saudi & 194 & 47.9 & 87 & 107 & & & \\
\hline \multicolumn{9}{|l|}{ Education level } \\
\hline & High School & 98 & 24.2 & 44 & 54 & \multirow{3}{*}{2} & \multirow{3}{*}{0.503} & \multirow{3}{*}{$\mathrm{N} / \mathrm{R}$} \\
\hline & Bachelor/diploma & 262 & 64.7 & 110 & 152 & & & \\
\hline & Master or PhD & 45 & 11.1 & 23 & 22 & & & \\
\hline \multicolumn{8}{|c|}{ Medical field employee or student } & \multirow{3}{*}{$\begin{array}{c}0.546 \\
\text { (Very strong) }\end{array}$} \\
\hline & Yes & 195 & 48.1 & 140 & 55 & 1 & $0.000 *$ & \\
\hline & No & 210 & 51.9 & 37 & 173 & & & \\
\hline \multicolumn{9}{|l|}{ Marital status } \\
\hline & Single & 240 & 59.3 & 6 & 114 & \multirow{3}{*}{2} & \multirow{3}{*}{$0.000^{*}$} & \multirow{3}{*}{$\begin{array}{c}0.215 \\
\text { (Strong) }\end{array}$} \\
\hline & Married & 145 & 35.8 & 44 & 101 & & & \\
\hline & Widowed or divorced & 20 & 4.9 & 7 & 13 & & & \\
\hline \multirow{2}{*}{$\begin{array}{l}\text { Do you know anyone } \\
\text { who had/has an STI? }\end{array}$} & Yes & 44 & 10.9 & 27 & 17 & \multirow{2}{*}{1} & \multirow{2}{*}{$0.012^{*}$} & 0.124 \\
\hline & No & 361 & 89.1 & 150 & 211 & & & (Moderate) \\
\hline
\end{tabular}

A Chi-square test was used to compare the differences between the categorical variables. \# Phi and Cramer's $\mathrm{V}$ tests were indicated to show the magnitude of the association in a significant value. ${ }^{*}$ Indicate a significant difference, $\mathrm{df}=$ degree of freedom, N/R $=$ not required.

participant. The knowledge level outcomes were coded as "Adequate" for scores equal or more than 10 (equal or more than 50\%) and as "Inadequate" for scores less than 10 (less than $50 \%$ ).

The third part, revolved around attitudes concerning STI-related factors and behaviors. The last part of the questionnaire began with a question on whether the participants were interested to learn more about STIs. Those who answered "yes" were offered educational slides (Supplementary material 2) followed by a series of questions designed to assess respondents' attitudes towards STI prevention and control. Based on the responses, the overall attitude was considered "positive" if for scores greater than or equal to six and scores or more out of seven and "negative" for scores less than or equal to five.

Cronbach's alpha was estimated at 0.837 and 0.866 for the "knowledge" and "attitude" sections of the questionnaire respectively. Face validity was evaluated by an expert panel of gynecologists who modified the questions to cater to cultural sensitivities and cover the high-yield areas pertinent to our population. Content validity was assessed by launching a small pilot study composed of the general population to ascertain the readability, clarity, and perceived relevance of the self-administered questionnaire prior to its distribution.

\subsection{Statistical analysis}

For descriptive statistics, we used frequencies and percentages. For univariate analyses, we used mean (M) and median (Me) to describe the central tendency and standard deviation (SD) to determine the dispersion between the variable's values. The Pearson Chi-Square test was used for bivariate analysis to evaluate the relationship between participants' sociodemographic characteristics and their level of knowledge about STIs. The Phi coefficient $(\varphi)$ or Cramer's V correlation (V) determined the intensity of the relationship and estimated the effect size when 
the Person Chi-Square test reflected a significant difference ( $p$ value $>0.05)$. The effect size of $\varphi$ or $\mathrm{V}$ tests was interpreted as following: very strong if $\varphi$ or $\mathrm{V}$ more than 0.25 , strong if $\varphi$ or $\mathrm{V}$ more than 0.15 , moderate if $\varphi$ or $\mathrm{V}$ more than 0.10 , weak if $\varphi$ or $\mathrm{V}$ more than 0.05 [24]. Moreover, independent-samples $t$-test and one-way ANOVA tests were used to compare the mean differences between two independent variables. Lastly, we used a bivariate Pearson correlation to evaluate the possible association between knowledge and attitude. All statistical analysis was carried out using SPSS statistics for windows 10, version 20.0 (Armonk, NY: IBM Corp).

\section{Results}

\subsection{Demographics and Social Characteristics}

Among the 420 total responses, 405 (96\%) participants were included based on completing all the assigned questions and having no missing data. There was a predominance of female participants at $(77 \%)$. More than half of the respondents were single (59\%), 24 years old or more (57\%), Saudi (52\%), and had a bachelor's degree (65\%). $48 \%$ of the participants were related to the medical field. Only 11\% know someone with an STI (Fig. 1). The social characteristics of the participants are shown in Table 1. Out of the sample population only 44 participants knew someone previously affected by an STI.

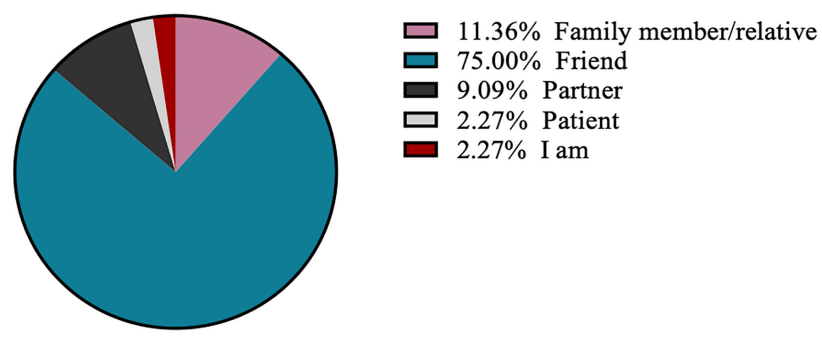

Total $=44$

Fig. 1. Individuals who are known by the participant to have STI. Notes that only 44 participants reported that they know someone had STI.

The mean score of overall knowledge about STI was $8.79 \pm 3.17($ median $=9)$. The lowest score was two, and the highest was 16 out of total 20 scores. Among our 405 participants, $56.3 \%$ of the participants were characterized to have an inadequate level of knowledge compared to only $43.7 \%$ that fell under the adequate level of knowledge category (Table 2).

\subsection{Assessment of Knowledge}

The participants were awarded points based on their knowledge of basic facts regarding STIs (See Supplementary material 2). The mean score of overall knowledge about STI was $8.79 \pm 3.17($ median $=9)$. The lowest score
Table 2. Knowledge level among participants on sexually transmitted illnesses $(n=405)$.

\begin{tabular}{llcccc}
\hline \multirow{2}{*}{ Level of knowledge Scores } & \multicolumn{2}{c}{ Statistics } & \multicolumn{3}{c}{ Responses } \\
\cline { 2 - 6 } & & Mean (SD) & Median & $n$ & $\%$ \\
\hline Adequate & $\geq 50 \%$ & $11.79(1.74)$ & 11 & 177 & 43.7 \\
Inadequate & $<50 \%$ & $6.46(1.75)$ & 7 & 228 & 56.3 \\
\hline
\end{tabular}

was 2, and the highest was 16 out of total 20 scores. A higher percentage of the participants $(56.3 \%)$ had an inadequate level of knowledge (Table 2).

\subsection{An Assessment of attitudes regarding STIS}

As demonstrated in Fig. 2, having multiple sexual partners (322) was perceived as the most significant risky behavior according to our questionnaire followed by out of wedlock relationships (291). Factors like unprotected sexual activity (258) and taking drugs (223) were also linked. Drinking alcohol (90) and traveling (64) were less affiliated with STI according to our participants. Practicing sports (0) was not a relevant behavior. Fig. 3 portrays the highest agreed upon methods of education in the following descending order starting with "lectures/teachers", "social media" and "parents/friends" by numbers 352, 294 and 266 of participants respectively. While 199 chose "brochures" and 182 chose "books". The least agreed upon method was "place-to-place campaigns" with a selection number of 84 participants. According to our study, 225 participants agreed that " $16-19$ " is the most appropriate age group, while 109 participants agreed on ' $13-15$ ' years of age and 66 chose " 20 years of age or above". This is demonstrated in Fig. 4. Fig. 5 represents the participants who believed informing the partner of a person with STI is mandatory. Among those $54.80 \%$ of participants chose "only the husband/wife" as the person responsible in informing his/her partner. While $26.01 \%$ selected "the doctor" as the correct person to inform the partner of the affected person and only $19.19 \%$ of the participants chose "health authorities" being the most suitable.

Awareness about the HPV vaccine amongst our studied population is depicted in Fig. 6. (A) presents the number of people aware of the HPV vaccine, (159) were aware of a vaccine however the majority were not aware of one (246). (B) A pie chart demonstrating the HPV vaccine obligation in Saudi Arabia, where an impressive 84.07\% think its mandatory and only $15.93 \%$ think it's not mandated out of 270 responses. (C) Addresses the reasons the (277) participants claim the HPV vaccine mandatory in KSA. The vast majority said the vaccine helps prevent a form of cancer (188), the second most voted reason was that unfaithful husbands with multiple wives will spread the infection (132). Similarly (130) participants responded with some people have more than one partner. The rest (119) responded that it was because people were sexually active. (D) Addresses the reasons the rest of the participants (43) claimed the HPV 


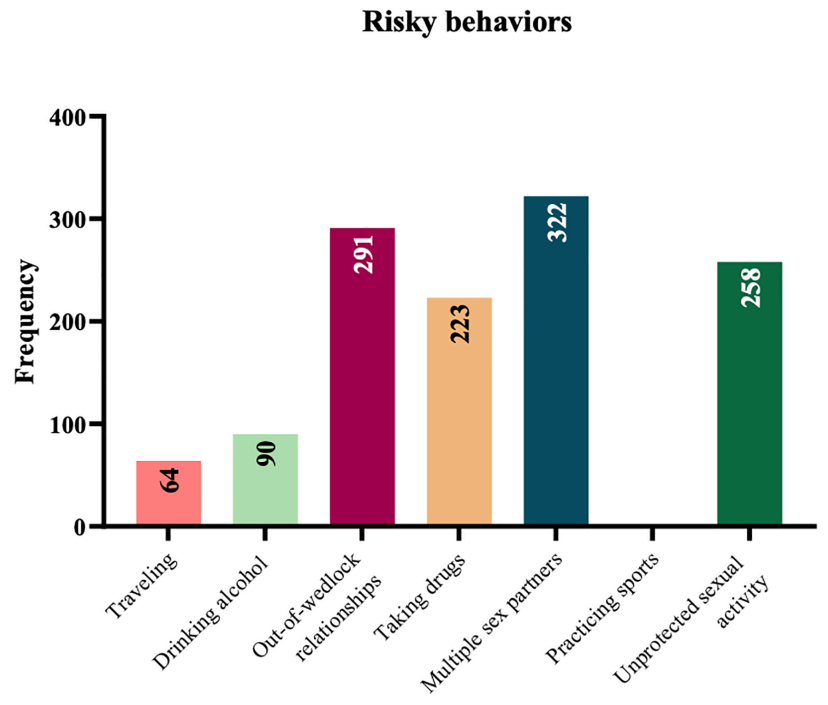

Fig. 2. Behaviors that the participants chose as risky sexual and behavioral practices to contract STI. Notes the participant was allowed to select one or more behaviors that would be a risk for STI according to their opinion. The frequency numbers represent the total number of times in which all participants choose selected behaviors.

\section{Appropriate method/s of education about STDs}

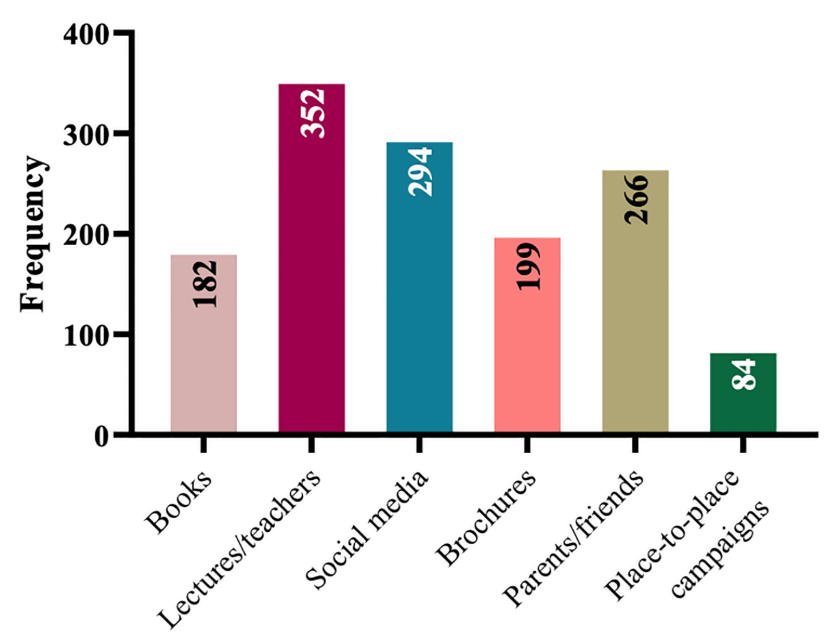

Fig. 3. Appropriate methods of education about STIs according to the opinion of the participants. Notes the participant was allowed to select one or more methods. The frequency numbers represent the total number of times in which selected behaviors are chosen by all participants.

vaccine was not necessary in KSA. The most sought-after response was that females in KSA are naturally protected from HPV though abstinence (25). Furthermore, some responded that the vaccine could encourage premarital sex (15), on the other hand the rest (15) claimed people in KSA

\section{Most appropriate age to start education about STDs}

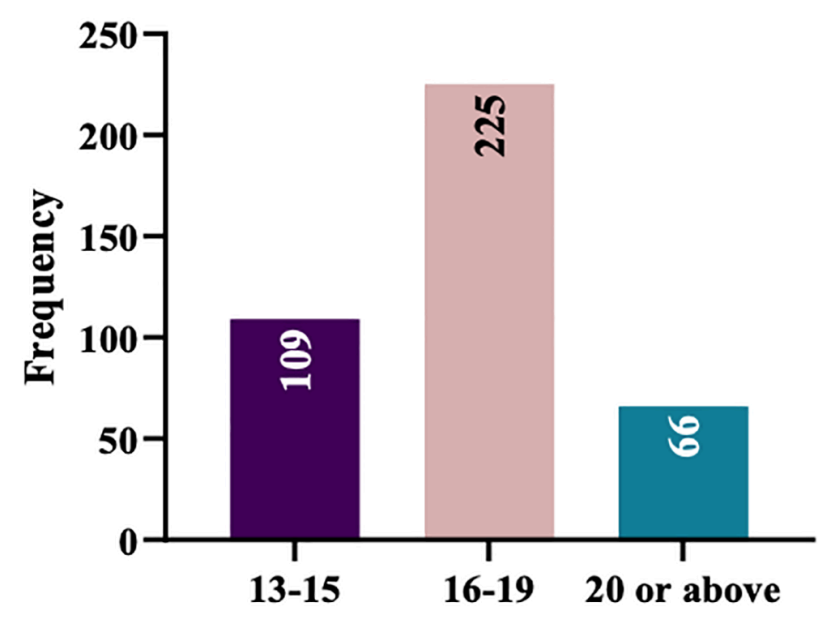

Fig. 4. Appropriate age for starting education about STIs according to the opinion of the participants. Notes the participant was allowed to select one answer only. There were 5 missing answers to this question.
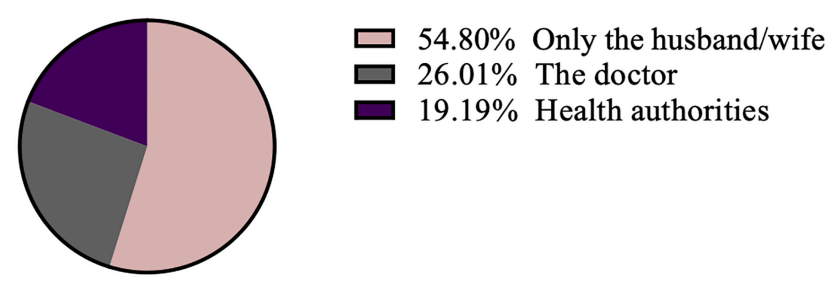

Total $=396$

Fig. 5. The person who is supposed to tell the partner about the presence of STI in his/her another partner. Note: The participant was allowed to select one answer only. Remain participants from the total $405(n=9)$ thought that informing the partner of a person with an STI is not mandatory.

don't have extramarital relation.

\subsection{Outcomes following survey completion}

A total of 281 out of 405 participants displayed an interest in accessing the educational material. The mean score for attitude was $5.89 \pm 1.52$ out of a total of seven (median $=6)$. The scores ranged from $0-7$ with $(72.60 \%)$ displaying a positive attitude towards STI education (Tables 3, 4, and $5)$.

\subsection{Association of knowledge and attitude}

As shown in Fig. 6, we found a significant correlation at the 0.05 level (2-tailed) regarding level of knowledge and attitude towards STIs. This is indicated by a positive direct 
a

Are you aware of the HPV vaccine?

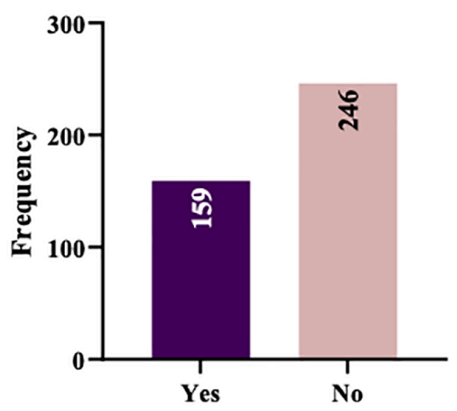

C b

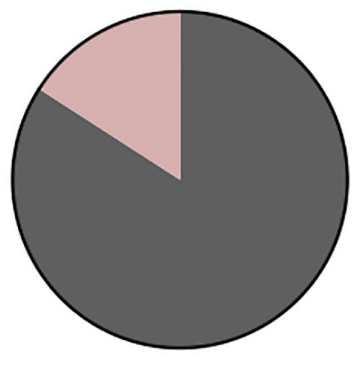

$84.07 \%$ The vaccine is mandatory in Saudi Arabia

$15.93 \%$ The vaccine is not necessary in Saudi Arabia

Total $=\mathbf{2 7 0}$

The vaccine is mandatory in

Saudi Arabia because $(n=227)$

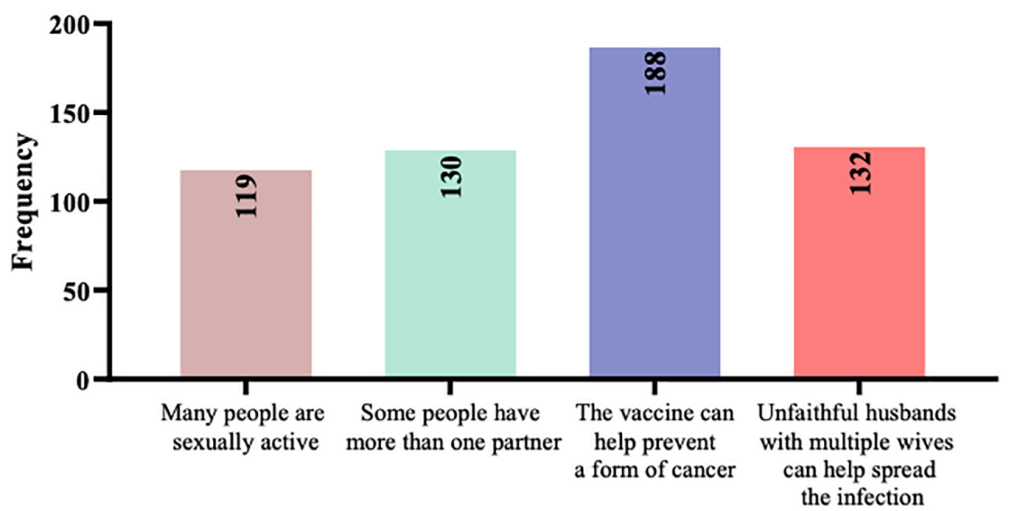

The vaccine is not necessary

in Saudi Arabia because $(n=43)$

d

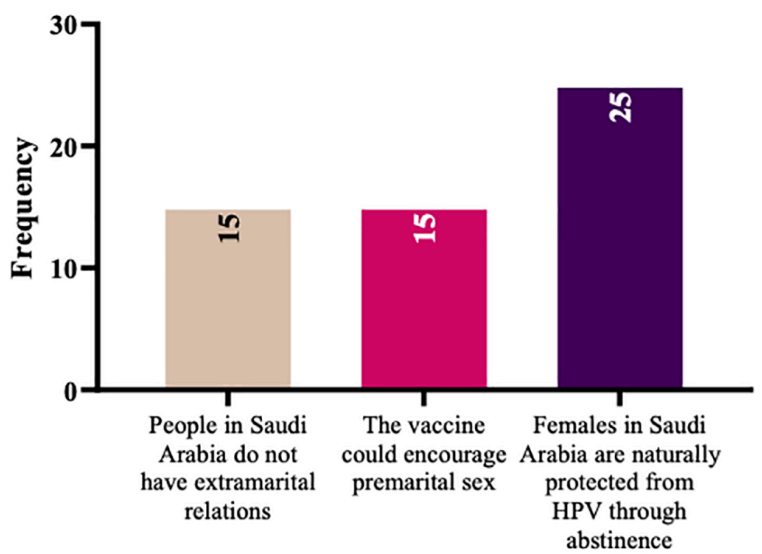

Fig. 6. Awareness and opinion about the human papilloma virus (HPV) vaccine. (a) Awareness about HPV vaccine. (b) Participants' opinion about the importance of the vaccine. (c) Justification why the vaccine is mandatory if the participants selected the first option. (d) Justification why the vaccine is not necessary if the participants preferred the second option. Notes the participant was allowed to choose one answer only in (a) and (b), and one or more answers in (c) and (d). Remain participants from the total (n=135) did not answer the last three questions. 
Table 3. The questions applied to assess the attitude towards sexually transmitted illnesses $(n=405)$.

\begin{tabular}{llcccc}
\hline & & & \multicolumn{3}{c}{ Responses } \\
\cline { 3 - 6 } No. & Item & Yes & \multicolumn{2}{c}{ No } \\
\cline { 3 - 6 } & & $n$ & $\%$ & $\%$ \\
\hline 1 & Are you interested in learning more about STI's? & 278 & 68.6 & 127 & 31.4 \\
2 & Are you more likely to get tested for STIs if your partner complains of painful urination? & 201 & 49.6 & 69 & 17.0 \\
3 & Are you more likely to get tested for STIs if your partner complains of genital lesions? & 256 & 63.2 & 12 & 3.0 \\
4 & Are you more likely to get tested for STIs if you have painful urination? & 207 & 51.1 & 61 & 15.1 \\
5 & Are you more likely to get tested for STIs if you notice skin changes/new lesions in your genital area? & 256 & 63.2 & 9 & 2.2 \\
6 & Are you interested in learning more about the HPV vaccine? & 228 & 56.3 & 40 & 9.9 \\
7 & Do you think that most STIs are manageable and should be treated promptly? & 230 & 56.8 & 38 & 9.4 \\
\hline
\end{tabular}

Table 4. Attitude towards sexually transmitted illnesses $(n=$ 281).

\begin{tabular}{lccc}
\hline \multirow{2}{*}{ Attitude } & \multirow{2}{*}{ Scores } & \multicolumn{2}{c}{ Responses } \\
\cline { 3 - 4 } & & $n$ & $\%$ \\
\hline Positive & $\geq 6$ & 204 & 72.60 \\
Negative & $\leq 5$ & 77 & 27.40 \\
\hline
\end{tabular}

$(\mathrm{n}=124)$ were excluded by choice.

weak-strength relationship with a significant positive correlation value of $p=0.041^{*}, \mathrm{r}=0.122$.

\section{Discussion}

In line with findings previously reported in the literature, a majority of our sample population had inadequate knowledge on STIs [10-12,15,25]. While we expected the younger age group to display a superior level of knowledge based on a generational shift on convictions on taboo topics, no statistically significant relationship was noted. Meanwhile, marital status was a surprisingly significant variable as the "single" category had the most superior level of knowledge while most of the "married" individuals fell under the "inadequate knowledge" score. This is reminiscent of another study targeting married female employees at a Saudi institution, which showed a poor overall level of knowledge on sexually transmitted illnsesses [26]. This shows that the married population, which is widely assumed to be the only sexually active subset of the Saudi population, does not have sufficient knowledge to recognize and seek treatment for STI symptoms.

Another notable finding is the statistically significant positive correlation between higher levels of knowledge and involvement in the medical field. This trend conveys the potential role of healthcare workers in enhancing public's awareness regrading this topic. This could be utilized to train current and future medical personnel to employ their knowledge in this field to raise awareness of basic knowledge through campaigns and their interactions with patients. Further questionnaires that test medical personnel's knowledge on STI-related guidelines and targeted ed- ucational interventions may be required to implement this. Another demographic factor of significance in relation to level of knowledge was prior knowledge of someone who has/had an STI, which was positively related to better outcomes. This may imply that the low incidence or reluctance to discuss such conditions with others may play a role in the low levels of public knowledge on the topic. This further highlights the importance of purposeful targeted educational initiatives to combat this limitation.

In extension of other papers' finding that many individuals depended on unreliable sources of information to acquire STI-related knowledge, [10] we found that 352/408 of our sample prefer to receive lectures in schools and universities. This reflects an openness to the implementation of sexual education at this level. This also parallels the dominant view that 16-19 age-group is the appropriate period for this intervention.

Despite the knowledge deficits highlighted by our study, $69 \%$ of the participants showed willingness to expand their knowledge at the time of survey completion, with $72.6 \%$ of them having a positive attitude on STI education. A positive correlation was found between knowledge and attitude (Fig. 7). These findings echo the results from an older descriptive study which pointed out the urgency of establishing preventive strategies over a decade ago [27]. On the importance of integrating STI knowledge into schoolbased curriculums: over $95 \%$ agreed in a large $(5000+)$ female predominant study [10]. A male-only study on male adolescents also revealed that $(92.3 \%)$ believed in the effectiveness of sex education and (85.6\%) agreed with the need for school-based sex education. Similarly, our participants believed that the optimal source of information on STIs was through lectures and teachers between ages 16-19.

Our results contrast to the results obtained from a previous analysis of STI knowledge among female inmates at a Saudi prison. Most participants were not aware of STIs and did not undergo screening for STIs and were unsure of the protective role of barrier contraceptives. Of note is the fact that over $50 \%$ of the participants had been imprisoned for charges related to prostitution [28]. Meanwhile, our participants correctly identified "risky behaviors" linked to STIs, 
Table 5. The association between attitudes and social characteristics $(n=281)$.

\begin{tabular}{|c|c|c|c|c|c|}
\hline \multirow{2}{*}{ Variables } & & \multirow{2}{*}{ Responses ( $n$ ) } & \multicolumn{2}{|c|}{ Attitude } & \multirow{2}{*}{$p$ value } \\
\hline & & & $M$ & $S D$ & \\
\hline \multicolumn{6}{|l|}{ Age } \\
\hline & Less than 24 & 139 & 6.01 & 1.41 & 0.187 \\
\hline & 24 or more & 142 & 5.77 & 1.62 & \\
\hline \multicolumn{6}{|l|}{ Gender } \\
\hline & Male & 59 & 5.88 & 1.42 & 0.946 \\
\hline & Female & 222 & 5.90 & 1.55 & \\
\hline \multicolumn{6}{|l|}{ Nationality } \\
\hline & Saudi & 146 & 5.86 & 1.47 & 0.730 \\
\hline & Non-Saudi & 135 & 5.93 & 1.58 & \\
\hline \multicolumn{6}{|l|}{ Education level } \\
\hline & High School & 70 & 6.00 & 1.39 & 0614 \\
\hline & Bachelor/diploma & 189 & 5.88 & 1.57 & 0.614 \\
\hline & Master or $\mathrm{PhD}$ & 22 & 5.64 & 1.50 & \\
\hline \multicolumn{6}{|l|}{ Medical field employee or student } \\
\hline & Yes & 156 & 5.99 & 1.43 & 0.217 \\
\hline & No & 125 & 5.77 & 1.63 & \\
\hline \multicolumn{6}{|l|}{ Marital status } \\
\hline & Single & 184 & 6.10 & 1.29 & \\
\hline & Married & 91 & 5.45 & 1.87 & $0.003^{*}$ \\
\hline & Widowed or divorced & 6 & 6.17 & 0.408 & \\
\hline \multirow{2}{*}{ Do you know anyone who had/has an STI? } & Yes & 31 & 5.48 & 2.08 & \multirow{2}{*}{0.112} \\
\hline & No & 250 & 5.94 & 1.43 & \\
\hline
\end{tabular}

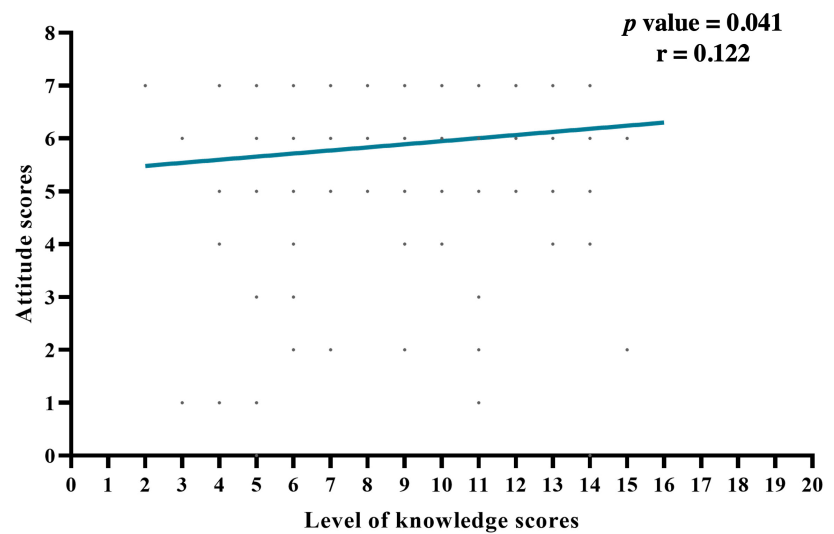

Fig. 7. Participants' level of knowledge in relation to their attitudes towards STI. Correlation is significant at the 0.05 level (2-tailed) and indicates a positive direct week-strength relationship.

while misconceptions previously reported by others [9] in similar populations were not widely present. For example, sports and travelling were not reported as "risky behavior" by our sample.

Interestingly, most of the participants showed an appreciation for preventive methods such as the HPV vaccine and falsely thought that it was mandatory. Upon completing the educational material, 230/281 participants ex- pressed their interest to learn more about the vaccine.

Of the participants who chose to access the educational material, a vast majority was able to recognize painful urination and genital lesions, affecting either the individual or their sexual partner, as a reason to seek medical attention. Furthermore, most of the participants recognized the importance of prompt management to establish positive outcomes and avoid complications. This shows the effectiveness of our simple educational initiative and underlines the necessity for widespread implementation of this concept.

Several limitations were noted during the conduction of our study. The sample size was not extensive and involved a high proportion of individuals in the medical field. In the future, we may proceed with a new questionnaire targeting the knowledge level that would be expected of medical field professionals to corroborate their potentials as advocates in this field. Furthermore, we created a questionnaire designed to question specific attitudes that the authors have encountered either among members of society or through interactions with patients, which is why we deviated from the questions employed by other standardized surveys. Therefore, it is difficult to incorporate our study with more extensive reviews that depended on commonly used standardized questionnaires. 


\section{Conclusions}

Our work highlights the deficits in public knowledge on STIs. Such deficits manifest through risky practices that could potentially promote the transmission of STIs. However, our results point to the participants' willingness to improve their knowledge on the topic, preferably through institutional and academic efforts beginning at an early age prior to the onset of sexual activity. Another positive aspect portrayed by our results, is the willingness to access educational material on STIs despite this being an optional component of the survey. The questions completed after exposure to this content also proved to be promising with participants recognizing common manifestations of STIs and the importance of early interventions.

Future research on the topic should be conducted with more rigorous sample selection, potentially allowing for further comparisons among different age groups, urban and rural settings, and various cultural variables that may influence knowledge and attitudes. Moreover, more extensive interventions with larger outreach efforts can be implemented with longer follow-up periods that explore how enhanced knowledge on STIs can influence sexual practices such as barrier contraceptive use and seeking medical attention upon recognizing STI symptoms. Further prospective studies can study the impact of this on STI incidence and primary care presentations. If applied, such efforts can be translated into policies that increase accessibility to proper counselling and therapeutic interventions.

Education is the pillar of preventive medicine and can lead to improved awareness, attitudes, and behaviors. The dismissal of STI-related education by the local community should be fought by integrating suitable educational material into official curriculums. Prior studies have highlighted the urgency of this intervention and our study substantiate those findings by highlighting the target population's willingness to embrace such interventions.

\section{Author contributions}

WF, MA, SF, and RB designed the research study. MA, BF, RB, RA, SS, SF, and SA carried out the data collection. $\mathrm{BF}$ and $\mathrm{SS}$ analyzed the data. $\mathrm{RB}$ wrote the manuscript. All authors contributed to editorial changes in the manuscript. All authors read and approved the final manuscript.

\section{Ethics approval and consent to participate}

The ethical approval was obtained from the Unit of Biomedical Ethics (King Abdulaziz University, Jeddah, Saudi Arabia). All participants agreed to participate in the study prior to completing the questionnaire, their identities remained anonymous throughout the study.

\section{Acknowledgment}

Not applicable.

\section{Funding}

This research received no external funding.

\section{Conflict of interest}

The authors declare no conflict of interest.

\section{Supplementary material}

Supplementary material associated with this article can be found, in the online version, at https://www.imrpre ss.com/journal/CEOG/49/1/10.31083/j.ceog4901026.

\section{References}

[1] Burton DC, Burris S, Mermin JH, Purcell DW, Zeigler SC, BullOtterson L, et al. Policy and Public Health. Public Health Reports. 2020; 135: 5S-9S

[2] Tjiam KH, Zeilmaker GH, Alberda AT, Polak-Vogelzang AA, Stolz E, Michel MF. Seksueel overdraagbare aandoeningen en infertiliteit. Ned Tijdschr Geneeskd, 1986, 130: 1403-1406.

[3] Hobbs E, Vera JH, Marks M, Barritt AW, Ridha BH, Lawrence D. Neurosyphilis in patients with HIV. Practical Neurology. 2018; 18: 211-218.

[4] Bradshaw D, Matthews G, Danta M. Sexually transmitted hepatitis $\mathrm{C}$ infection: the new epidemic in MSM? Current Opinion in Infectious Diseases. 2013; 26: 66-72.

[5] Inoue T, Tanaka Y. Hepatitis B virus and its sexually transmitted infection - An update. Microbial Cell. 2016; 3: 420-437.

[6] Leeper C, Lutzkanin A. Infections during Pregnancy. Primary Care. 2018; 45: 567-586.

[7] Wagenlehner FME, Brockmeyer NH, Discher T, Friese K, Wichelhaus TA. The Presentation, Diagnosis, and Treatment of Sexually Transmitted Infections. Deutsches Arzteblatt International. 2017; 113: 11-22.

[8] Baazeem A. Challenges to Practicing Sexual Medicine in the Middle East. Sexual Medicine Reviews. 2018; 4: 221-228.

[9] Balbeesi A, Mohizea S. Knowledge and misconceptions of Saudi women about sexually transmitted infections. Journal of Egyptian Public Health Association. 2017; 92: 235-239.

[10] El-Tholoth HS, Alqahtani FD, Aljabri AA, Alfaryan KH, Alharbi F, Alhowaimil AA, et al. Knowledge and attitude about sexually transmitted diseases among youth in Saudi Arabia. Urology Annals. 2019; 10: 198-202.

[11] Alsubaie ASR. Examining HIV and STIs Related Knowledge among Male Adolescents in Saudi Arabia. the Open AIDS Journal. 2020; 14: 27-34.

[12] Albanghali MA, Othman BA. A cross-sectional study on the knowledge of sexually transmitted diseases among young adults living in albaha, Saudi Arabia. International Journal of Environmental Research and Public Health. 2020; 17: 1872.

[13] Filemban SM, Yasein YA, Abdalla MHH, Al-Hakeem R, AlTawfiq JA, Memish ZA. Prevalence and behavioral risk factors for STIs/HIV among attendees of the Ministry of Health hospitals in Saudi Arabia. Journal of Infection in Developing Countries. 2016; 9: 402-408.

[14] Memish ZA, Filemban SM, Al-Hakeem RF, Hassan MH, AlTawfiq JA. Sexually transmitted infections case notification rates in the Kingdom of Saudi Arabia, 2005-2012. The Journal of Infection in Developing Countries. 2016; 10: 884-887.

[15] Barss P, Grivna M, Ganczak M, Bernsen R, Al-Maskari F, El Agab H, et al. Effects of a Rapid Peer-Based HIV / AIDS Educational Intervention on Knowledge and Attitudes of High School Students in a High-Income Arab Country. Journal of Acquired Immune Deficiency Syndromes. 2009; 52: 86-98.

[16] Alsbeih G. HPV Infection in Cervical and other Cancers in Saudi 
Arabia: Implication for Prevention and Vaccination. Frontiers in Oncology. 2014; 4: 65.

[17] Iyemosolo BM, Chivese T, Esterhuizen TM. A comparison of the prevalence of sexually transmitted infections among circumcised and uncircumcised adult males in Rustenburg, South Africa: a cross-sectional study. BMC Public Health. 2021; 21: 656.

[18] Drain PK, Halperin DT, Hughes JP, Klausner JD, Bailey RC. Male circumcision, religion, and infectious diseases: an ecologic analysis of 118 developing countries. BMC Infectious Diseases. 2007; 6: 172.

[19] Raheel H, Mahmood MA, BinSaeed A. Sexual practices of young educated men: implications for further research and health education in Kingdom of Saudi Arabia (KSA) Journal of Public Health. 2013; 35: 21-26.

[20] Alsubaie ASR. Exploring Sexual Behaviour and Associated Factors among Adolescents in Saudi Arabia: a Call to End Ignorance. Journal of Epidemiology and Global Health. 2019; 9: 76.

[21] Aldhaleei WA, Bhagavathula AS. HIV/AIDS-knowledge and attitudes in the Arabian Peninsula: a systematic review and metaanalysis. Journal of Infection and Public Health. 2020; 13: 939948.

[22] Alwafi HA, Meer AMT, Shabkah A, Mehdawi FS, El-Haddad $\mathrm{H}$, Bahabri N, et al. Knowledge and attitudes toward HIV/AIDS among the general population of Jeddah, Saudi Arabia. Journal of Infection and Public Health. 2018; 11: 80-84.

[23] Jaworski BC, Carey MP. Development and psychometric evaluation of a self-administered questionnaire to measure knowledge of sexually transmitted diseases. AIDS and Behavior. 2007; 11: 557-574.

[24] Kim H. Statistical notes for clinical researchers: Chi-squared test and Fisher's exact test. Restorative Dentistry \& Endodontics. 2019; 42: 152-155.

[25] AlQuaiz AM, Kazi A, Al Muneef M. Determinants of sexual health knowledge in adolescent girls in schools of Riyadh-Saudi Arabia: a cross sectional study. BMC Women'S Health. 2013; 13: 19.

[26] Al-batanony MA. Knowledge, Attitude and Practices about Sexually Transmitted Infections/Sexually Transmitted Diseases (STIs / STDs) among Married Employee Ladies in Qassim Province, KSA. International STD Research \& Reviews. 2016; $1-10$.

[27] Madani TA. Sexually transmitted infections in Saudi Arabia. BMC Infectious Diseases. 2006; 6: 3.

[28] Fageeh WM. Sexual behavior and knowledge of human immunodeficiency virus/aids and sexually transmitted infections among women inmates of Briman Prison, Jeddah, Saudi Arabia. BMC Infectious Diseases. 2014; 14: 1-7. 